\title{
Investigation of the Effect of Friction Stir Spot Welding of BH Galvanized Steel Plates on Process Parameters and Weld Mechanical Properties
}

\author{
Hamed Sheikhhasani \\ Department of Materials Engineering \\ Karaj Branch, Islamic Azad \\ University \\ Karaj, Iran \\ hamedsheikhhasani@yahoo.com
}

\author{
Hamed Sabet \\ Department of Materials Engineering \\ Karaj Branch, Islamic Azad \\ University \\ Karaj, Iran \\ h-sabet@kiau.ac.ir
}

\author{
Mehrdad Abasi \\ Department of Materials Engineering \\ Karaj Branch, Islamic Azad \\ University \\ Karaj, Iran \\ mabbasi@kiau.ac.ir
}

\begin{abstract}
This study evaluates the effect of Friction Stir Spot Welding (FSSW) pin shape on overlapping galvanized BH plates. FSSW is done at 4, 6 and 9 seconds dwell time at two rotational speeds (1500 and $1800 \mathrm{rpm}$ ) by tools with 10 and $14 \mathrm{~mm}$ shoulder diameter. Microstructural properties (OM and SEM), Vickers micro hardness and tension are tested on the welded spots. By increasing shoulder diameter from 10 to $14 \mathrm{~mm}$ to joint two plates, microstructural grain size decreases by $23 \%$ in $\mathrm{SZ}$ and $15 \%$ in TMAZ. Maximum fracture increases as shoulder diameter increases to $32 \%$.
\end{abstract} Shape

Keywords-Friction Stir Spot Welding; Galvanized steel BH; Pin

\section{INTRODUCTION}

Steel is the main material for structures of light and heavy vehicles. The emphasis on corrosion protection and safety has led to the increased utilization of galvanized steel in vehicles. However, galvanized steel welding causes some technical problems for producers and end consumers due to the certain differences between galvanized steel and similar uncoated steel. Compared to low carbon steel, different electrical or physical properties lead to completely different weld ability and connection [1]. Due to its advantages, Friction Stir Welding (FSW) is used in different industries. A particular FSW process developed in the automotive industry is Friction Stir Spot Welding (FSSW), which provides high quality joints. FSSW galvanized steel is considered as a challenging alternative. However, little is known on the effect of FSSW parameters on steel joints. According to some claims, FSSW results in $90 \%$ savings in energy and $40 \%$ savings in equipment. Moreover, investment and operating costs of FSSW are relatively lower compared to Resistance Spot Welding (RSW). Hence, FSSW is considered as an alternative for RSW [2-6]. Four main FSSW parameters include rotation speed (in rpm), tool shape, plunge depth and dwell time (interaction time). In FSSW, a cylindrical rotating tool with a protruding pin plunges at a specific rate into the overlapping plates to a predetermined depth. It is then retracted rapidly either immediately or after the dwell period. The frictional heat generated softens the metal; the rotating pin causes material flow in both lateral and axial directions. The forging pressure exerted by the shoulder forms an annular, solid-state bond around the pin. The retracted pin leaves a characteristic exit hole. Figure 1 depicts a scheme of FSSW [7-13]. This study evaluates the effect of FSSW tool shape on overlapping galvanized $\mathrm{BH}$ plates.

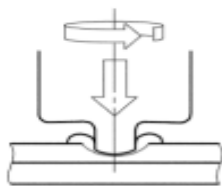

(a)

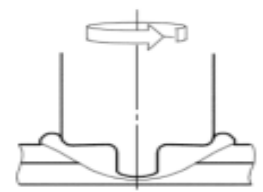

(b)

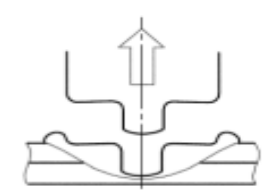

(c)
Fig. 1. schema of FSSW steps (a) Plunging; (b) Stirring; (c) Retracting.

\section{EXPERIMENT}

Galvanized steel BH plates (0.7 $\mathrm{mm}$ in thickness) are used for the experiments. Tables I and II list the mechanical properties and composition of base material. FSSW is performed by a CNC milling machine, made in USA. Tungsten Carbide tools with a convex scrolled shoulder and a protruding pin is used for FSSW as shown in Figure 2. In absence of a quality standard for FSSW, a RSW standard (AWS-D17.2) is used as a reference [14]. Tensile shear is tested on butt-welded plates $(175 \times 25 \mathrm{~mm})$ with an overlapping joint $(25 \times 25 \mathrm{~mm})$, as shown in Figure 3.

FSSW parameters include Z-axis force, tool RPM, depth of penetration and dwell time. The milling machine was used is able to control the position where the required Z-axis force is automatically applied by the machine. The welding parameters adopted include $8 \mathrm{~mm} / \mathrm{min}$ feed rate (FR) at Z- axis, 1500 and $1800 \mathrm{rpm}$ rotation, $0.9 \mathrm{~mm}$ depth of penetration ( include 0.7 
$\mathrm{mm}$ depth of pin and $0.2 \mathrm{~mm}$ depth of shoulder ) and 4-9 $\mathrm{s}$ dwell time (DT). The diameter considered for each joint is an average of three specimens. Tension of different FSSW specimens is tested by a 1-ton static tension test machine ( 5 $\mathrm{mm} / \mathrm{min}$ crosshead speed). The load values reported are an average of three welded specimens with similar parameters. The cross-section of welded specimens is mechanically sanded, polished and etched by $5 \%$ nital. A microscope is used to observe the microstructure. Traverse micro hardness is tested on the polished and etched specimens under $30 \mathrm{GF}$ load.

TABLE I. CHEMICAL COMPOSITION (WT\%) OF THE USED BH PLATE

\begin{tabular}{|c|l|}
\hline $\mathrm{C}$ & 0.006 \\
\hline $\mathrm{Si}$ & 0.006 \\
\hline $\mathrm{S}$ & 0.012 \\
\hline $\mathrm{P}$ & 0.016 \\
\hline $\mathrm{Mn}$ & 0.328 \\
\hline $\mathrm{Ni}$ & 0.017 \\
\hline $\mathrm{Cr}$ & 0.013 \\
\hline $\mathrm{V}$ & 0.001 \\
\hline $\mathrm{Cu}$ & 0.006 \\
\hline $\mathrm{Al}$ & 0.035 \\
\hline $\mathrm{Zn}$ & 0.011 \\
\hline
\end{tabular}

TABLE II. MECHANICAL PROPERTIES OF THE BASE METAL BH

\begin{tabular}{|c|c|c|c|c|}
\hline Material & UTS (MPa) & YS (MPa) & Elongation (\%) & Hardness (V) \\
\hline $\begin{array}{c}\text { Back } \\
\text { Hardanable } \\
\text { (BH) }\end{array}$ & 300 & 189 & 41 & 107 \\
\hline
\end{tabular}
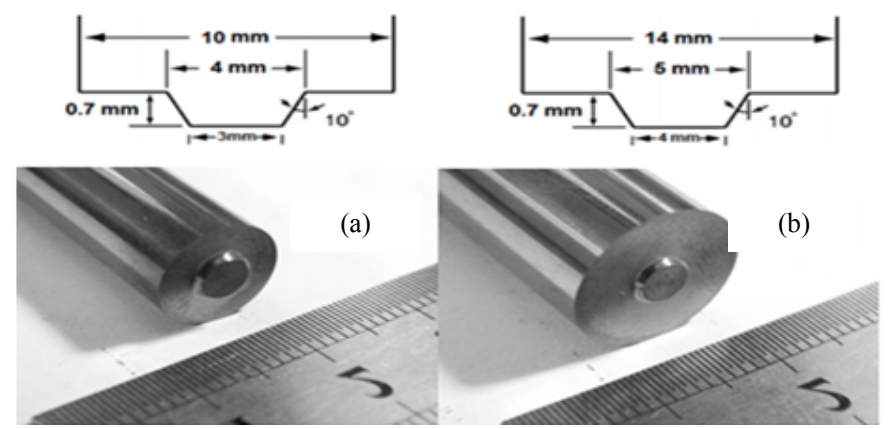

Fig. 2. Tungsten Carbide tools used in this study with different shoulder diameters; a) $10 \mathrm{~mm}$; b) $14 \mathrm{~mm}$.

\section{RESULTS AND DISCUSSION}

\section{A. Microstructure of the Welded Joint}

Figure 4 shows a schematic cross section of a FSSW joint. Three zones are clear: i) Stirred zone (SZ); ii) Thermo mechanically affected zone (TMAZ); iii) Base metal (BS). The approximate position of these zones is shown in the macro graphic transverse section of a FSSW specimen. FSSW material experiences severe plastic deformation and high temperature caused by friction. Tool shape influences material flow.

Figure 5 shows a soft coarse-grained ferritic $\mathrm{BH}$ microstructure. SZ microstructure consists of fine-grained ferrite (Figures 6a and 7a). In SZ under the shoulder, the penetrating and rotating pin and shoulder exert a mechanical work and produce heat. In general, the heat is produced by the rotating pin when the shoulder contacts the plate. However, the plates are thin and the heat is largely produced by the shoulder contacting the plate. Therefore, dynamic recrystallization will occur during simultaneous exertion of work and heat. As shown in Figures 6a and 7a, the upper SZ which is close to the pin is quickly cooled by retracting the pins from the plate; therefore, the recrystallized grains will not grow. This will provide a very fine microstructure.

By traversing from SZ to TMAZ, the grain size will progressively be enlarged (Figures $6 \mathrm{~b}$ and $7 \mathrm{~b}$ ). TMAZ is further away from the pin; therefore, the effect and the work of the rotating pin are lower than SZ. Thus, TMAZ is influenced by heat, rather than mechanical work. Static recrystallization will occur in TMAZ. Thermal conductivity of steel is lower than that of aluminum; therefore, cooling rate is lower and grains will spend more time at high temperature. As a result, the recrystallized grains will grow. The increase in shoulder diameter leads to a reduction in $\mathrm{SZ}$ grain size; this reduction will increase as the rotation speed and dwell time increase. Moreover, the increase in shoulder diameter increases TMAZ grain size. In general, TMAZ grains including polygonal ferrite and pearlite are finer than base material.

Table III and Figure 8 show the changes in grain size for BM, SZ and TMAZ. In addition, Figure 9 compares different specimens; obviously, the shift from tool 1 to the tool 2 (10 $\mathrm{mm}$ shoulder diameter to $14 \mathrm{~mm}$ shoulder diameter) leads to $23 \%$ reduction in SZ grain size and $15 \%$ reduction in TMAZ grain size, on average.Another important factor in determining the good joints is the bond width. Figure 10 is a close-up view of $\mathrm{BH}$ joint. Clearly, upper and lower work pieces are metallurgically bonded around the penetrating pin. The bond width is a critical factor determining the strength of the joint, which is relatively good in this study.

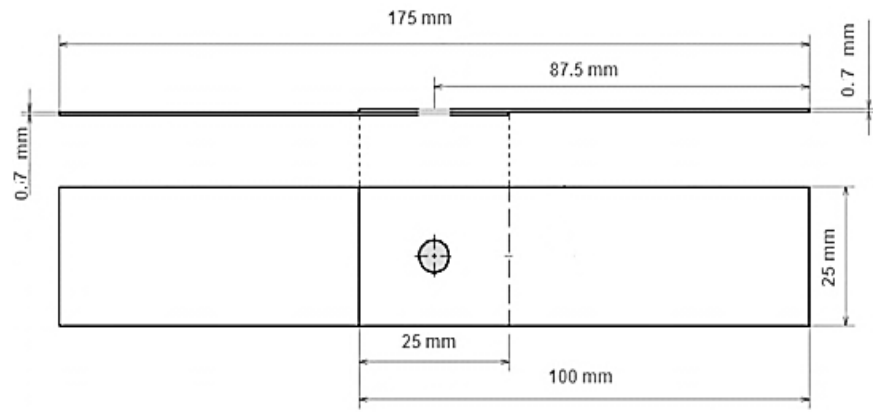

Fig. 3. Tensile shear test in accordance with AWS-D17.2

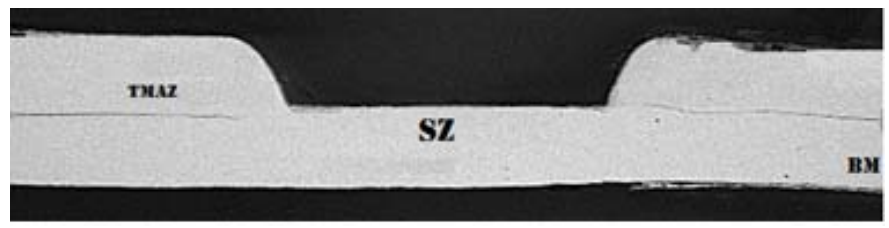

Fig. 4. Macro graphic FSSW joint for Galvanized BH plate 


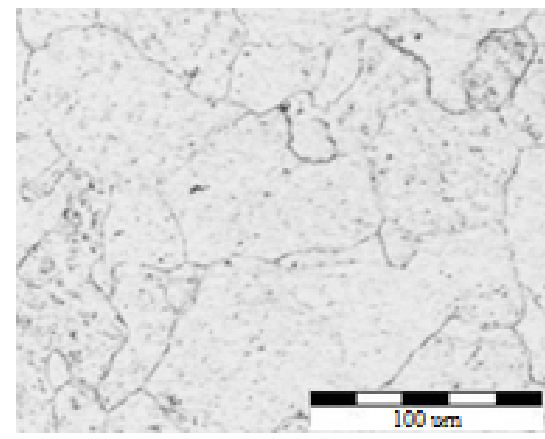

Fig. 5. Microstructural $\mathrm{BH}$

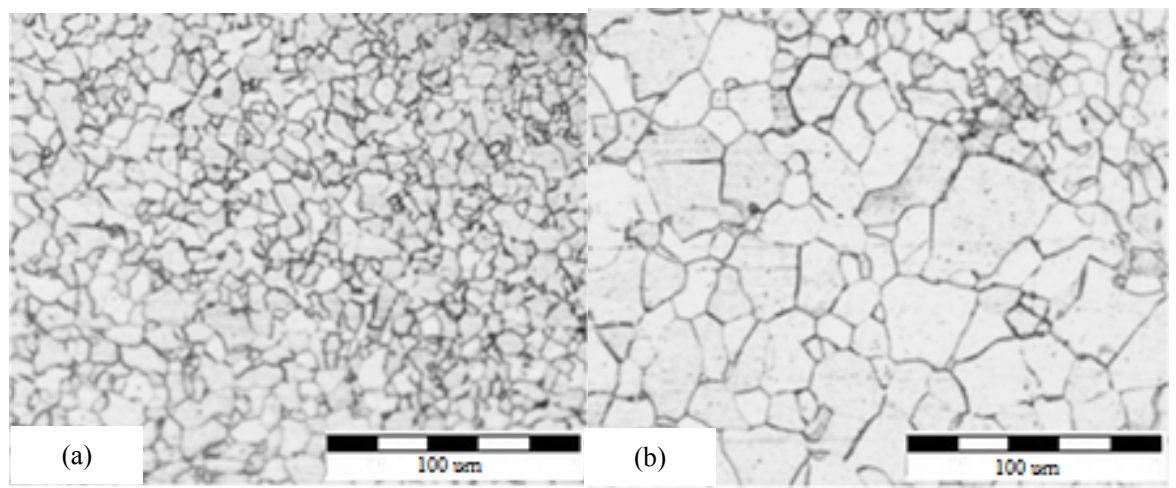

Fig. 6. Microstructural FSSW (a) SZ, (b) TMAZ (1800 rpm, pin 2)
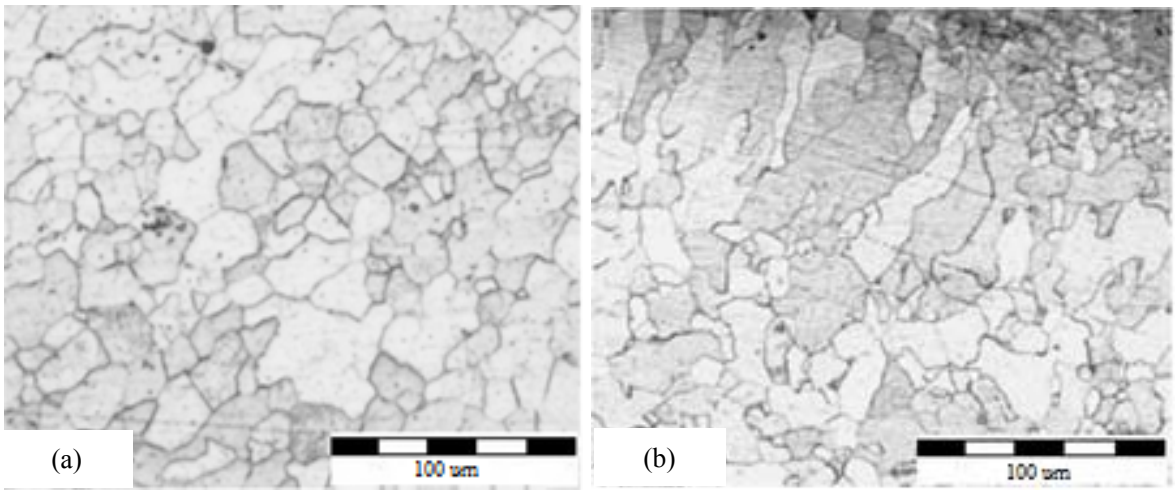

Fig. 7. Microstructural FSSW (a) SZ, (b) TMAZ (1800 rpm, pin 1)

TABLE III. SZ AND TMAZ GRAIN SIZES

\begin{tabular}{|c|c|c|c|c|c|}
\hline Specimen & Dwell time (s) & Rotation speed (rpm) & Diameter (mm) & SZ grain size (mm) & TMAZ grain size (mm) \\
\hline 1 & 4 & 1800 & 10 & 6.80 & 13.00 \\
\hline 2 & 6 & 1800 & 10 & 6.10 & 11.42 \\
\hline 3 & 9 & 1800 & 10 & 5.70 & 10.00 \\
\hline 4 & 4 & 1500 & 10 & 8.00 & 13.62 \\
\hline 5 & 6 & 1500 & 10 & 7.20 & 12.10 \\
\hline 6 & 9 & 1500 & 10 & 6.25 & 10.00 \\
\hline 7 & 4 & 1800 & 14 & 5.80 & 11.42 \\
\hline 8 & 6 & 1800 & 14 & 5.15 & 9.50 \\
\hline 9 & 9 & 1800 & 14 & 4.30 & 8.50 \\
\hline 10 & 4 & 1500 & 14 & 6.20 & 11.89 \\
\hline 11 & 6 & 1500 & 14 & 6.00 & 10.00 \\
\hline 12 & 9 & 1500 & 14 & 4.90 & 9.89 \\
\hline
\end{tabular}




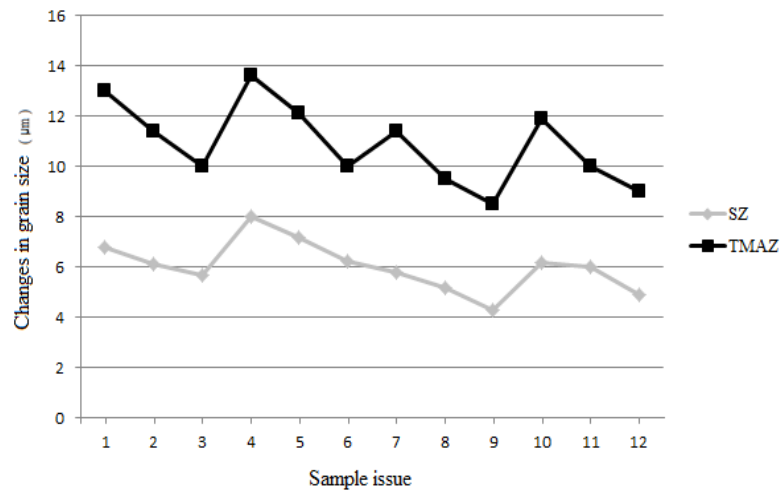

Fig. 8. Variations in SZ and TMAZ grain size

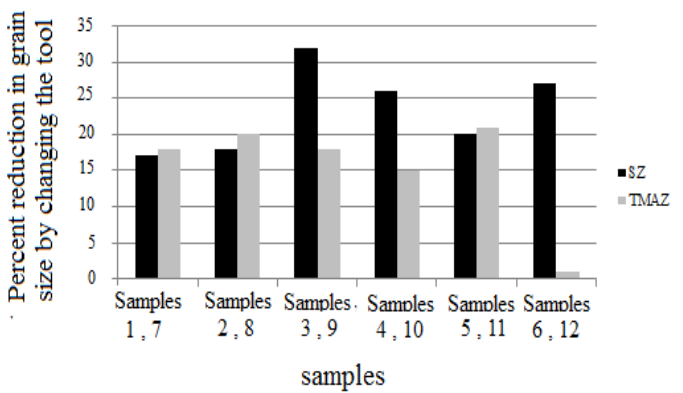

Fig. 9. Changes in grain size by the changes in tools for the compared joints

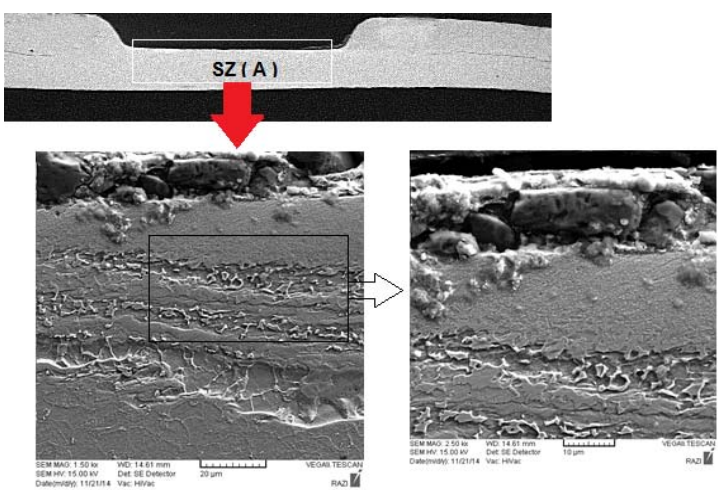

Fig. 10. Intersection of the joint. Galvanized steel BH, $9 \mathrm{~s}$ dwell time, pin 2

\section{B. Mechanical Properties of Joints: Tension-Shear and Micro hardness}

Table IV reports the results of tension test for joints. Note that, one of the goals of tension-shear test is to determine the mechanically reasonable or unreasonable properties of the joints. Tension of a welded specimen is reasonable when the fracture locally occurs around the nugget in the base metal, or the upper plate, entirely or partially, remains as a nugget at least on the lower plate.

As shown in Table IV, the increase in shoulder diameter leads to an increase in friction, heat and fracture which increases by higher rotation speed and dwell time (Figures 11 and 12). The increase in shoulder diameter leads to an increase in friction, thereby more input heat; this increases SZ volume and eventually causes fracture.

TABLE IV. RESULTS OF TENSION-SHEAR TEST ON SPOT WELDED JOINTS

\begin{tabular}{|c|c|c|c|c|c|c|}
\hline Specimen & $\begin{array}{l}\text { Tension } \\
\text { (N) }\end{array}$ & $\begin{array}{c}\text { Dwell time } \\
\text { (s) }\end{array}$ & $\begin{array}{c}\text { Rotation speed } \\
\text { (rpm) }\end{array}$ & $\begin{array}{c}\begin{array}{c}\text { Diameter } \\
(\mathrm{mm})\end{array} \\
\end{array}$ & Fracture position & group \\
\hline 1 & 2486 & 4 & 1800 & 10 & Fracture in joint & 1 \\
\hline 2 & 2838 & 6 & 1800 & 10 & Fracture in joint & 1 \\
\hline 3 & 3067 & 9 & 1800 & 10 & Fracture in base metal & 3 \\
\hline 4 & 1600 & 4 & 1500 & 10 & Fracture in joint & 1 \\
\hline 5 & 2770 & 6 & 1500 & 10 & Fracture in joint & 1 \\
\hline 6 & 3023 & 9 & 1500 & 10 & Fracture in base metal & 3 \\
\hline 7 & 3419 & 4 & 1800 & 14 & Fracture around the nugget & 2 \\
\hline 8 & 3838 & 6 & 1800 & 14 & Fracture around the nugget & 2 \\
\hline 9 & 5026 & 9 & 1800 & 14 & Fracture in base metal & 3 \\
\hline 10 & 3210 & 4 & 1500 & 14 & Fracture around the nugget & 2 \\
\hline 11 & 3750 & 6 & 1500 & 14 & Fracture around the nugget & 2 \\
\hline 12 & 4020 & 9 & 1500 & 14 & Fracture in base metal & 3 \\
\hline
\end{tabular}

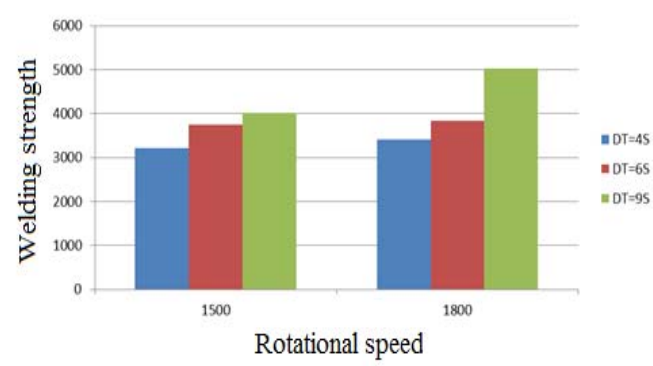

Fig. 11. Welding strength versus rotation speed at the dwell times for pin 2

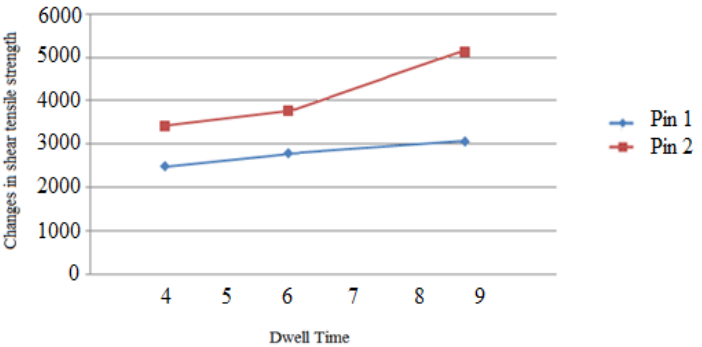

Fig. 12. Comparison of tension-shear curves versus dwell time for different pins 
Figure 13 shows the fracture levels and cross section of the lap shear specimens joined at two different shoulder diameters. There is a marked change in the fracture position as the shoulder diameter increases. Fractures also show the exact shear strength of the specimens. Based on their fracture behavior, joints can be divided into three groups: 1) through the fracture, the upper plate partially remains under the lower plate (Figure 13a), 2) cracks occur and expand around the nugget and concave shoulder (Figure 13b), 3) cracks occur and expand farther away from the nugget and in base metal (Figure 13c). In the first group, nugget is small, SZ is limited and cannot penetrate enough into the lower plate. Thus, the bond is weak. In the second group, the nugget is small, SZ is limited and cracks start to propagate and expand in SZ around the nugget and the upper plate which becomes thinner by the penetrating shoulder. In the third group for which the tool with larger shoulder diameter is used, nugget is larger, suggesting that SZ penetrates enough into the lower plate; in this case, fracture occurs mostly in base metal. Accordingly, strength is lower in the first group than the second group and in both groups than the third group where fracture occurs in the base metal. As shown in Figure 14, the shift from tool 1 to tool 2 (changing the shoulder diameter from $10 \mathrm{~mm}$ to $14 \mathrm{~mm}$ ) increases the fracture by $32 \%$, on average.

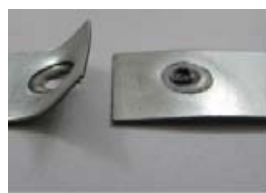

(a)

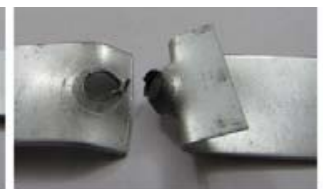

(b)

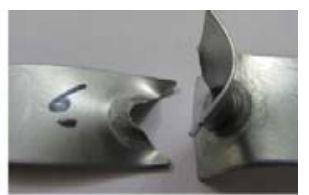

(c)
Fig. 13. Iypes of tractures in the tension-shear test

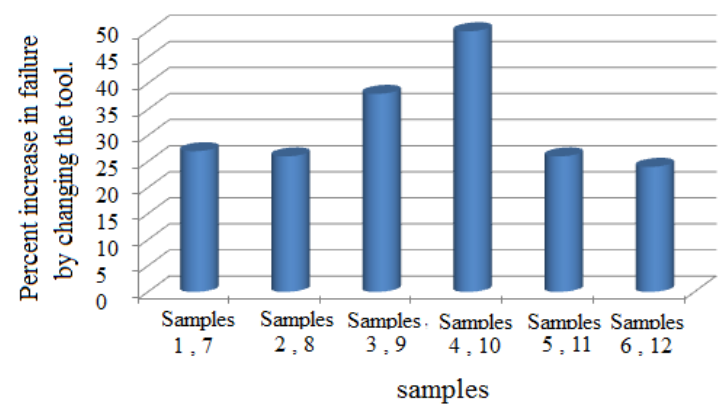

Fig. 14. The increase in fracture (\%) by changing the tool for compared specimens

Figures 15 and 16 show the variations in micro hardness by changing tool, dwell time and rotation speed. The highly hard zone corresponds to SZ. SZ and TMAZ micro hardness increases as the shoulder diameter increases to $14 \mathrm{~mm}$. The average hardness of the base metal is about $107 \mathrm{HV}$. The maximum SZ hardness is seen in the joints welded by tool 2 in 9s dwell time, $1800 \mathrm{rpm}$. In general, SZ and TMAZ micro hardness will increase as the shoulder diameter, rotation speed and dwell time increase. Therefore, higher SZ and TMAZ hardness results from larger grain boundaries compared to BM.

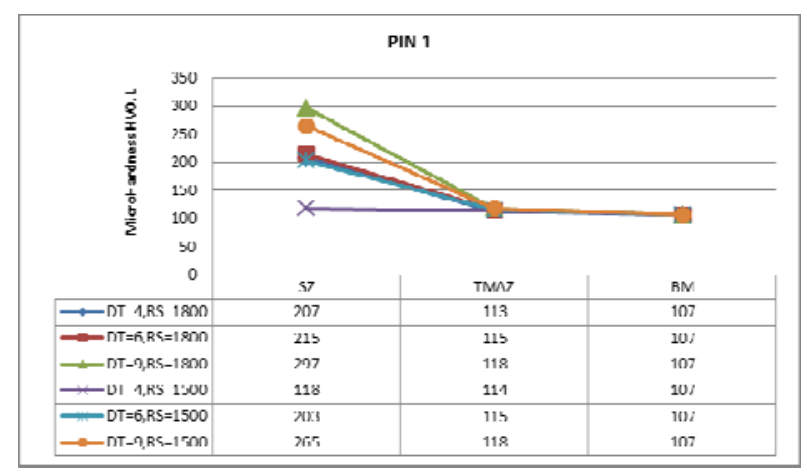

Fig. 15. Variations in hardness versus distance from nugget (shoulder diameter $10 \mathrm{~mm}$ )

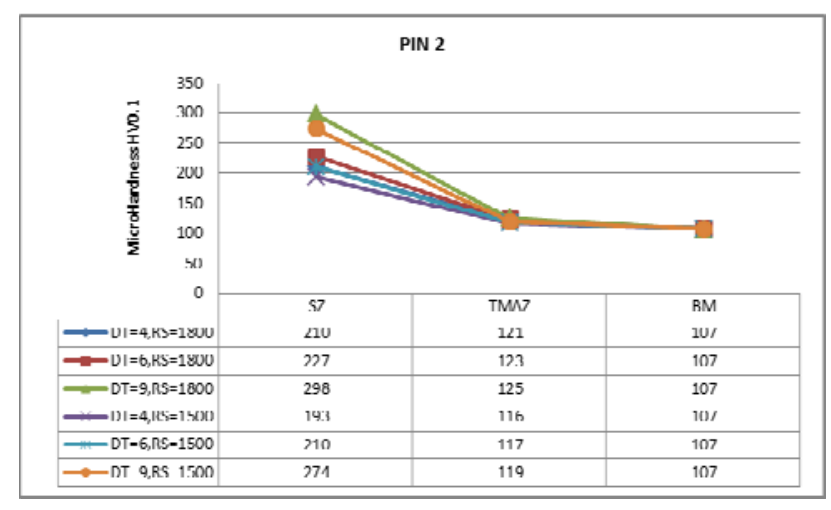

Fig. 16. Variations in hardness versus distance from nugget (shoulder diameter $14 \mathrm{~mm}$ )

In general, there is a direct relationship between reduced grain size and increased strength and hardness; in fine-grained structures, fracture is higher and thus the joint is stronger.

\section{CONCLUSION}

The main results found in this paper can be summarized as:

1. Tool shoulder diameter directly influences the strength and microstructure of FSSW galvanized steel joints.

2. The increased shoulder diameter from 10 to $14 \mathrm{~mm}$ reduces the grain size in SZ and TMAZ microstructure by $23 \%$ and $15 \%$, on average. Moreover, the increased shoulder pin diameter increases fracture) by $32 \%$.

3. Based on tool shoulder diameter, rotation speed and dwell time, fracture of the specimens can be divided to three groups.

4. The highest fracture $(5026 \mathrm{~N})$ is related to the joint welded by the tool with $14 \mathrm{~mm}$ shoulder diameter, $1800 \mathrm{rpm}$ rotation speed and $9 \mathrm{~s}$ dwell time.

5. By increasing shoulder diameter, rotation speed and dwell time of the tool, mechanical work and consequently heat will increase and the grain sizes will be dramatically reduced. Thus, hardness will increase in the welded zone. However, moving away from the joint will reduce hardness, which results from the increased grain sizes. 


\section{REFERENCES}

[1] S. W. Baek, D. H. Choi, C. Y. Lee, B. W. Ahn, Y. M. Yeon, K. Song, S. B. Jung, "Microstructure and mechanical properties of friction stir spot welded galvanized steel", The Japan Institute of Metals, pp.1044-1050, 2010

[2] J. M. Piccini, H. G. Svoboda, "Effect of pin length on Friction Stir Spot Welding (FSSW) of dissimilar aluminum-steel joint", Procedia Materials Science, Vol. 9, pp. 504-513, 2015

[3] A. Gerlich, P. Su, T. H. North, "Tool penetration during friction stir spot welding of Al and Mg alloyes", Journal of Materials Science,Vol. 40, pp. 6473-6481, 2005

[4] M. Awang, "Simulation of Friction Stir Spot Welding (FSSW) process: Study of friction phenomena", PhD thesis, College of Engineering and Mineral Resources, West Virginia University, 2007.

[5] J. Zhang, Y. Shen, B. Li, H. Xu, X. Yao, B. Kuang, J. Gao , "Numerical simulation and experimental investigation on friction stir welding of 6061-T6 aluminum alloy", Materials \& Design, Vol. 60, pp. 94-101, 2014

[6] V. X. Tran, J. Pan, T. Pan, "Effects of processing time on strengths and fracture modes of dissimilar spot friction welds between aluminum 5754-O and 7075-T6 sheets", Journal of Materials Processing Technology, Vol. 209, pp. 3724-3739, 2008

[7] Y. Tozaki, Y. Uematsu, K. Tokaji, "Effect of tool geometry on microstructure and static strength in friction stir spot welded aluminium alloys", International Journal of Machine Tools \& Manufacture, Vol. 47, pp. 2230-2236, 2007

[8] M. Awang, V. H. Mucino, Z. Feng, S. A. David, "Thermo-mechanical modeling of Friction Stir Spot Welding (FSSW) process use of an explicit adaptive meshing scheme", Science and Engineering, Vol. 01, pp. 1251-1256, 2006

[9] S. Venukumar, S. Yalagi, S. Muthukumaran, "Comparison of microstructure and mechanical properties of conventional and refilled friction stir spot welds in AA 6061-T6 using filler plate", Transactions of Nonferrous Metals Society of China, Vol. 23, No. 10, pp. 2833-2842, 2013

[10] H. Badarinarayan, Y. Shi, X. Li, K. Okamoto,"Effect of tool geometry on hook formation and static strength of friction stir spot welded aluminum 5754-O Sheets", International Journal of Machine Tools \& Manufacture, Vol. 49, pp. 814-823, 2009

[11] A. Gerlich, P. Su, M. Yamamoto, T. H. North, "Effect of welding parameters on the strain rate and microstructure of friction stir spot welded 2024 aluminum alloy", Journal of Material Science, Vol. 42, pp. 5589-5601, 2007

[12] C. Gao, R. Gao, Y. Ma , "Microstructure and mechanical properties of friction spot welding aluminium-lithium 2A97 alloy", Materials \& Design, Vol. 83, No. 15, pp.719-727, 2015

[13] J. M. Piccini, H. G. Svoboda, "Effect of the tool penetration depth in Friction Stir Spot Welding (FSSW) of dissimilar aluminum alloys", Procedia Materials Science, Vol. 8, pp. 868-877, 2015

[14] G. Buffa, L. Fratini, M. Piacentini, "On the influence of tool path in friction stir spot welding of aluminum alloys", Journal of Materials Processing Technology, Vol. 208, pp. 309-317, 2008 